\title{
Increasing the germination percentage of a declining native orchid (Himantoglossum adriaticum) by pollen transfer and outbreeding between populations
}

\author{
S. Del Vecchio ${ }^{1}$ (D) S. Pierce ${ }^{2}$ (D), E. Fantinato ${ }^{1}$ (D) \& G. Buffa ${ }^{1}$ (iD \\ 1 Department of Environmental Science, Informatics and Statistics, Ca' Foscari University, Venice, Italy \\ 2 Department of Agricultural and Environmental Sciences (DiSAA), University of Milan, Milan, Italy
}

\section{Keywords}

Conservation; cross-pollination; dry grasslands; isolation; population size.

\section{Correspondence}

S. Del Vecchio, Department of Environmental Science, Informatics and Statistics, Ca' Foscari University, Venice, Italy.

E-mail: silvia.delvecchio@unive.it

Editor

H. Pritchard

Received: 10 January 2019; Accepted: 19 March 2019

doi:10.1111/plb.12986

\section{ABSTRACT}

- The declining native orchid Himantoglossum adriaticum H. Baumann is a European endemic of priority interest (92/43/ EEC, Annex II). Northern Italian populations of $H$. adriaticum are small and isolated, with depressed seed set. Given the important implications for plant population conservation, we tested the hypothesis that artificial pollen transfer (hand-pollination) and outbreeding between populations increases fruit set and seed germination percentage.

- The background fruit set and in vitro germination rates were determined for ten reference populations. An artificial cross-pollination experiment included (a) pollen transfer from one large population to two small and isolated populations; (b) pollen transfer between two small but not isolated populations; (c) within-population pollen transfer (control). All seeds were sown on a modified Malmgren's medium and cultured in a controlled environment. Germination percentage was compared using a Kruskal-Wallis ANOva.

- The background fruit set (mean $=18 \%)$ and germination $(<5 \%)$ rates were consistently low across populations. Fruit set after hand-pollination was consistently $100 \%$. Pollen transfer from the largest population to smaller populations resulted in an increase in total germination ranging from $0.9 \%$ to $2.9 \%$. The largest increase in germination occurred between small-sized and less isolated populations (from $1.7 \%$ to $5.1 \%)$.

- The results of pollen transfer between the small populations are particularly encouraging, as the mean increase in germination was almost four times that of the control. Outbreeding can be considered a valuable tool to increase genetic flow and germination in natural populations, limit the accumulation of detrimental effects on fitness driven by repeated breeding with closely-related individuals, thereby increasing the possibility of conservation of rare or endangered species.

\section{INTRODUCTION}

The declining native orchid Himantoglossum adriaticum $\mathrm{H}$. Baumann is a European endemic species of priority interest (Directive 92/43/ EEC, Annex II), suffering population declines in many European countries (Dostalova et al. 2013). Its range comprises Austria, Bosnia-Herzegovina, Croatia, Czech Republic, Hungary, Italy, Slovakia and Slovenia (Dostalova et al. 2013). In Italy, it is mostly found in dry grasslands and nearby ecotonal meso-xeric scrubland/woodland patches (Slaviero et al. 2016), but it can also occur in secondary habitats such as roadsides and vineyards (Fekete et al. 2017).

In common with other orchid species, its vulnerability stems from particular requirements for germination, seedling establishment and reproduction (e.g. Slaviero et al. 2016; Fantinato et al. 2017; Magrini \& De Vitis 2017). Pollen transfer is mainly carried out by pollinating insects (wasps, bees, bumblebees, butterflies, flies and night-flying insects; Fantinato et al. 2017) that are attracted through a sophisticated mechanism.
Himantoglossum species are non-rewarding, since there is no evidence of nectar in the spur and they are believed to lure pollinators with a male goat smell (Carey \& Farrell 2002; Fantinato et al. 2017). The pollination system of food deceptive orchids, which do not offer any food reward to their pollinators, is particularly problematic and has been thought to determine a low visitation rate, since pollinators learn to avoid deceptive flowers, resulting in a low fruit set due to pollination limitation (Pellissier et al. 2010).

Although often being species- and life stage-specific, seed germination and growth of orchid seedlings or adult plants rely on symbiosis with mycorrhizae (Rasmussen 2002; Pecoraro et al. 2013). Seeds are extremely small and light, contain few nutrient reserves, and may have morphological and morphophysiological dormancy, often imposing a low germination percentage (Baskin \& Baskin 2014). Indeed, the reproductive success of $H$. adriaticum is generally low, being characterised by low fruit set (between 5 and 45\%; Biró et al. 2015) and low germination percentage (Gilián et al. 2018). 
The persistence of populations is also threatened by habitat destruction and fragmentation due to land-use change (Fischer \& Lindenmayer 2007; Buffa et al. 2018; Fantinato et al. 2019). In particular, the increase in human settlements and infrastructure, the spread of industrialised agriculture and the abandonment of low-intensity agricultural regimes, such as grazing and mowing, have been evoked as the main causes of dry grassland decline (Janišová et al. 2011; Fantinato et al. 2016a). Habitat fragmentation creates small and/ or isolated populations, often found in residual patches which frequently lack suitable environmental conditions for the proliferation of rare and endangered species with specific ecological requirements.

Small and isolated populations exhibit low fecundity, which results in a negative feedback on the population size (Hens et al. 2017). Compared with large populations, small and isolated populations have increased extinction risk because of reduced gene flow, which leads to a shift in allele frequencies and a reduction in alleles and genotypes (Oostermeijer 2003). Small and isolated populations also suffer from inbreeding (Angeloni et al. 2011), which often results in reduced reproduction and offspring survival (Charlesworth \& Charlesworth 1987; Keller \& Waller 2002; Lienert 2004) because of increasing homozygosity.

Individuals in small populations may also experience reduced viability and reproduction for demographic reasons. By limiting pollinator movement among patches, fragmentation may also reduce the abundance and richness of pollinator populations and alter their foraging behaviour (Aguirre \& Dirzo 2008; Fantinato et al. 2019). Small and isolated plant populations thus likely receive fewer flower visits and smaller pollen loads, thereby suffering pollen limitation, reduction in reproductive success and low seed quality (Jacquemyn \& Brys 2015).

The negative effects described above can be alleviated through gene flow and outbreeding, which consist of the transfer of genetic material between different populations, either in the form of seeds, plants or pollen. Cross-pollination has been proven to enhance offspring fitness, increasing fruit set, fruit size and mass (Hill et al. 2006; Spinardi \& Bassi 2012). This technique has been widely used historically in agronomy to improve crops (Goldman 1998). Cross-pollination has also been tested for other orchid species (Pierce et al. 2010; see Tremblay et al. 2005 for review), demonstrating that orchids that were given supplemental pollination had higher levels of fruit set than those pollinated naturally. In conservation biology, artificial cross-pollination may thus represent an important tool for the conservation of rare and endangered species, especially those characterised by a complex life cycle and often by fragmented populations (Hill et al. 2006).

In light of these considerations, the aim of this work was to test the germination capacity of $H$. adriaticum and test the efficacy of artificial pollen transfer (hand-pollination) and outbreeding between populations in order to increase fruit set and germination percentage. The hypothesis tested was that individuals of $H$. adriaticum from isolated and smaller-sized populations fertilised with pollen originating from larger, non-isolated populations would exhibit higher fruit set and germination capacity under controlled conditions than when pollinated using pollen from within the population.

\section{MATERIAL AND METHODS}

\section{Study area and population selection}

The study was carried out in northern Italy, in the Veneto region, specifically in the Lessini, Berici and Euganei Hills. Mean annual temperature is $13{ }^{\circ} \mathrm{C}$, and annual rainfall range from 850 to $1200 \mathrm{~mm}$ (www.arpa.veneto.it/bollettini/htm/da ti_idrometeo.asp).

Dry grasslands develop on mid-altitude limestone slopes (47-443 $\mathrm{m}$ a.s.l.) with an average $\mathrm{pH}$ of 7.5 (Fantinato et al. 2016b, 2018). They have established and been maintained by traditional human management until a few decades ago, when drastic changes in the local socio-economic patterns triggered the abandonment of mowing, haymaking and pasturing practices, thereby causing surface reduction, fragmentation and species loss (Buffa et al. 2016). However, the area still represents a significant hotspot for dry grassland orchid diversity (Rizzieri Masin \& Tietto 2006).

We selected ten populations of $H$. adriaticum growing in the most suitable habitat conditions and used these as reference populations to test germination percentage of the species in the study area (Fig. 1). The population size varied between ten and 100 shoots, with a mean \pm SE of $42.5 \pm 13.7$. To estimate the reproductive fitness of each population, we measured the fruit set by calculating the fruit/flower ratio. We marked ten individuals for each population and counted the number of flowers. At fruiting, we counted the number of fruits on these marked individuals. We then selected three small populations consisting of approximately 30 shoots (a size comparable with those of the reference populations) and one large population ( $>500$ shoots) to test the effect of outbreeding on fruit set and germination percentage. Two of the small populations (P1 and $\mathrm{P} 2$ ) were only $0.5 \mathrm{~km}$ apart from one another, separated by an agro-forest matrix (consisting mainly of olive groves and maize fields). The other small population (P3) was separated from the others by a larger distance $(\sim 5 \mathrm{~km})$ and by an urban matrix. The large population (P4) was selected at a much longer distance $(\sim 20 \mathrm{~km})$ from the others, separated by an urban matrix. According to our experimental design, a small chance of naturally occurring cross-pollination is possible only between $\mathrm{P} 1$ and $\mathrm{P} 2$, which are the only populations separated by an agro-forest matrix within a short distance. Seed dispersal is also unlikely, as $99 \%$ of orchid seeds fall within $1 \mathrm{~m}$ of the parent plant (Jersáková \& Malinová 2007), with long-distance dispersal possible only during extremely rare climate events.

\section{Pollen transfer}

To test the effectiveness of outbreeding in increasing fruit set and total germination, pollen was artificially transferred (handpollination) from: (i) the large population (P4) to the two small and isolated populations (P2 and P3); (ii) between the two small but not very isolated populations (from P2 to P1); (iii) within-population (on the small populations, P1, P2 and $\mathrm{P} 3$ ), used as a control. Considering the small size of the recipient populations, pollen transfer was made on one quarter of the shoots of $H$. adriaticum in order to avoid excessive artificial manipulation of the population. The fruit/flower ratio was calculated after hand-pollination for all crosses. 


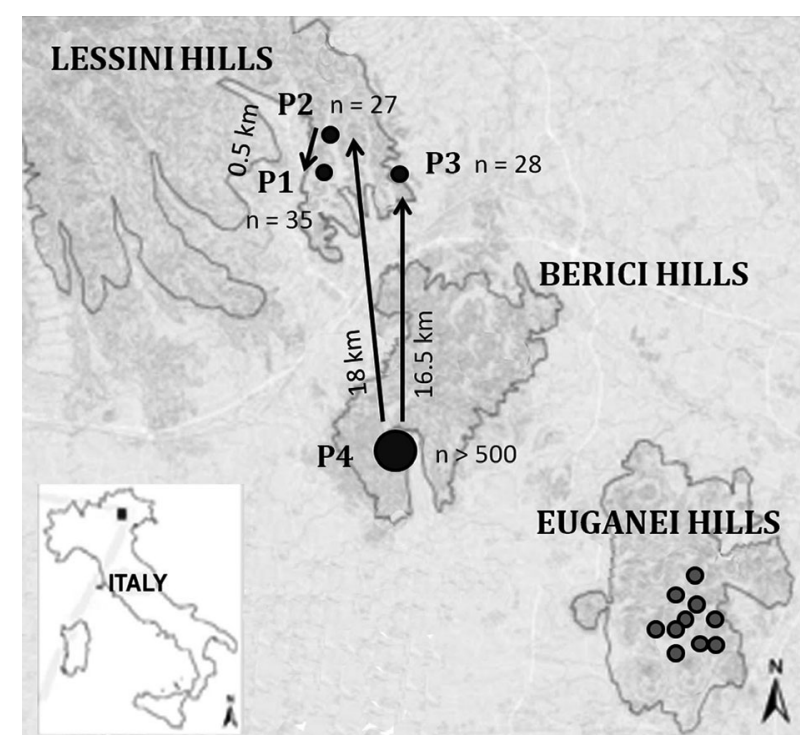

Fig. 1. Study area and sampling design. The arrows indicate the pollen transfer for the cross-pollination experiment, while ' $n$ ' indicates the number of shoots in each population. Dark grey populations were used for the outbreeding experiment; light grey populations were used as the reference populations to investigate the background germination capacity of Himantoglossum adriaticum

Ripened pollinia (dark grey in colour) were collected from 10 to 50 (depending on the population size) healthy H. adriaticum shoots at the peak of the flowering season in 2016 (i.e. third week of May) using toothpicks. To prevent desiccation before use, pollinia were placed in 9-cm diameter Petri dishes, sealed in the field with paper adhesive tape and kept in a coolbag $\left(15 \pm 2{ }^{\circ} \mathrm{C}\right)$ until returning to the lab facilities, where they were stored in the refrigerator $\left(4^{\circ} \mathrm{C}\right)$. The day after collection, pollinia were used to pollinate target shoots of the target population.

Healthy shoots selected for hand-pollination were marked with a transparent plastic label. To avoid accidental autogamy, all pollinia were removed and used for within-population pollination (control). Also, flowers that had already been pollinated were removed from the target shoots. Tagged shoots were monitored weekly after pollination to check for fruit development and maturation. Ripened capsules were harvested in the last week of June. All fruits were cleaned by hand in the lab, and stored in airtight vials in a freezer for 3 months, after dehydration at $15^{\circ} \mathrm{C}$ and $15 \% \mathrm{RH}$ following the FAO international standard (FAO 2014).

\section{Germination tests}

Seeds were soaked in a solution of $0.8 \% \mathrm{NaOCl}$ (equivalent to $0.5 \%$ active chlorine) for $15 \mathrm{~min}$, mainly for surface sterilisation (Wilson 1915) but also to weaken the hard structure of the seed testa, which is likely to hinder germination due to low water permeability (Rasmussen 1995). Successively, seed were sown in a sterile environment on agar medium in 6-cm diameter ventilated Petri dishes under a laminar flow hood (Mod. 1200 FLO; Permax Srl, Milano, Italy). Malmgren's orchid medium (Malmgren 1996) was used, modified with the addition of
$0.5 \mathrm{~g} \cdot \mathrm{l}^{-1}$ peptone and $0.1 \mathrm{~mm}$ 6-benzylaminopurine (BAP), since these compounds are proven to be effective in aiding germination of several terrestrial orchid species (Pierce et al. 2010, 2015; Pierce \& Cerabolini 2011).

Seed samples were sown in a growth chamber (Snijders Economic Deluxe; Thermo-Lab, Codogno, Italy) at $20 / 10{ }^{\circ} \mathrm{C}$ day/ night for 6 months. Eleven to 20 replicates were prepared according to the amount of seed available, resulting in 195 Petri dishes for the reference populations and 262 Petri dishes for the within- and between-population crosses. Petri dishes were checked monthly for evidence of germination. Seeds were checked using a stereomicroscope and were considered germinated when the embryo swelled sufficiently to split the seed coat and form a white protocorm (i.e. the seed entered developmental phase II, following Butcher \& Marlow 1989). Total germination was recorded 6 months after sowing, when no further germination was observed.

\section{Data analyses}

To explore the reproductive capacity of $H$. adriaticum, we compared fruit set, the proportion of fertilised and unfertilised seed and the germination percentage of the fertilised seed for the ten reference populations. Then we compared fruit set and germination percentage of within- and between-population pollination to test for the effect of outbreeding. We used Kruskal-Wallis ANOVA, with multiple comparisons, because data distribution was not normal, even after transformation (arcsin, $\log +1$, or square root transformations). Analyses were performed using the Statistica 8 (2007; Statistica, Hamburg, Germany) software package.

\section{RESULTS}

Himantoglossum adriaticum showed a low percentage fruit set and extensive variability across populations (mean $\pm \mathrm{SD}$ : $18 \% \pm 14 \%$; Fig. 2; Kruskal-Wallis test for the fruit set percentage: $\mathrm{H}=52.4, P<0.0001)$. Overall, the number of unfertilised seeds was high $(30.0 \% \pm 12.1 \%)$ although very variable across populations (Fig. 3A; Kruskal-Wallis test: $\mathrm{H}=143.3$, $P<0.0001$ ), while the germination percentage was very low, consistently $<5 \%$ (Fig. 3B; Kruskal-Wallis test: $\mathrm{H}=45.5$, $P<0.0001)$.

Pollen transfer had the same effect for both control and treatment groups, resulting in a fruit/flower ratio of $100 \%$ (Fig. 4A). Pollen transfer produced a significant increase in total germination percentage between all control and all treatment medians (Kruskal-Wallis test: $\mathrm{H}=43.64, P<0.0001$; Fig. 4). Pollen transfer from the largest to the smaller populations produced a positive effect only for population P3 (small and isolated population), whose median total germination increased from $0.9 \%$ to $2.9 \%$ (multiple comparisons: $\mathrm{z}=3.22, \quad P=0.019$; Fig. $4 \mathrm{~B}$ ), while $\mathrm{P} 2$ had no significant variation (from $0.8 \%$ to $1.6 \% ; z=2.16, P=0.46)$. Cross-pollination between small-sized populations produced the largest increase in total germination (P1; from $1.7 \%$ to $5.1 \%, \mathrm{z}=3.11, P=0.028$; Fig. 4 ).

\section{DISCUSSION}

Himantoglossum adriaticum consistently exhibited low fruiting and germination percentages across populations, often $<5 \%$ in 


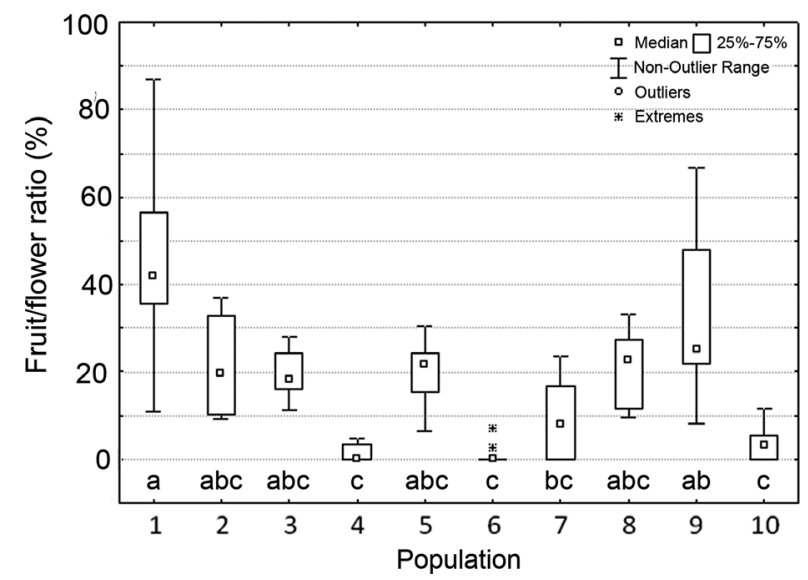

Fig. 2. Fruit set proportion, expressed as percentage of the fruit/flower ratio of the ten reference populations of Himantoglossum adriaticum. Boxes with different letters are significantly different according to the multiple comparison test.

A

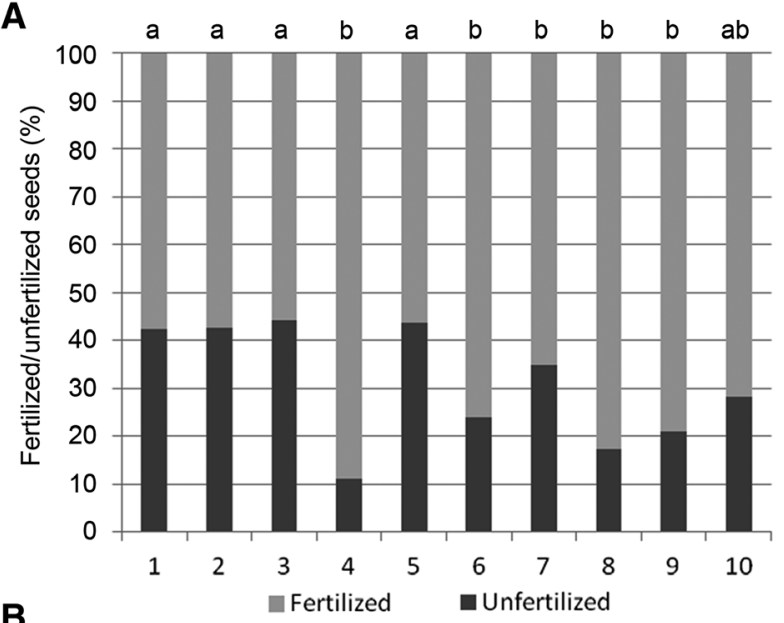

B

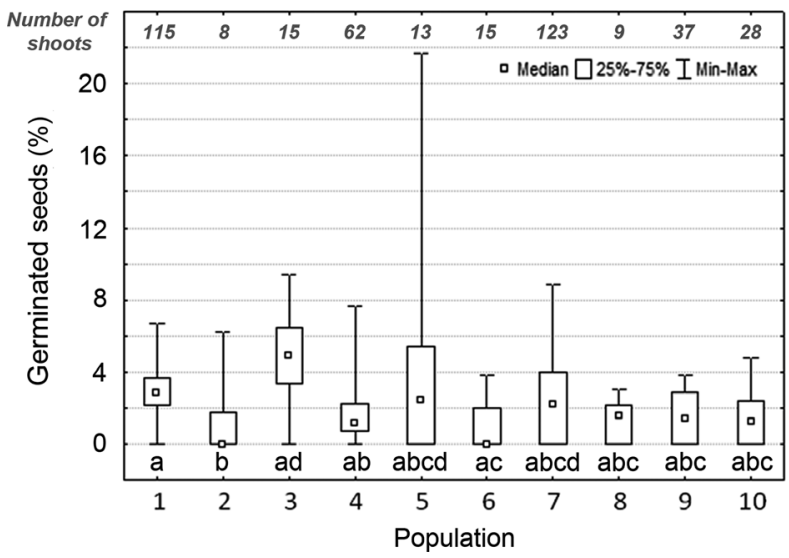

Fig. 3. Proportion of fertilised seeds (A) and germination percentage (B) of the ten reference populations of Himantoglossum adriaticum. Boxes with different letters are significantly different according to multiple comparison test.
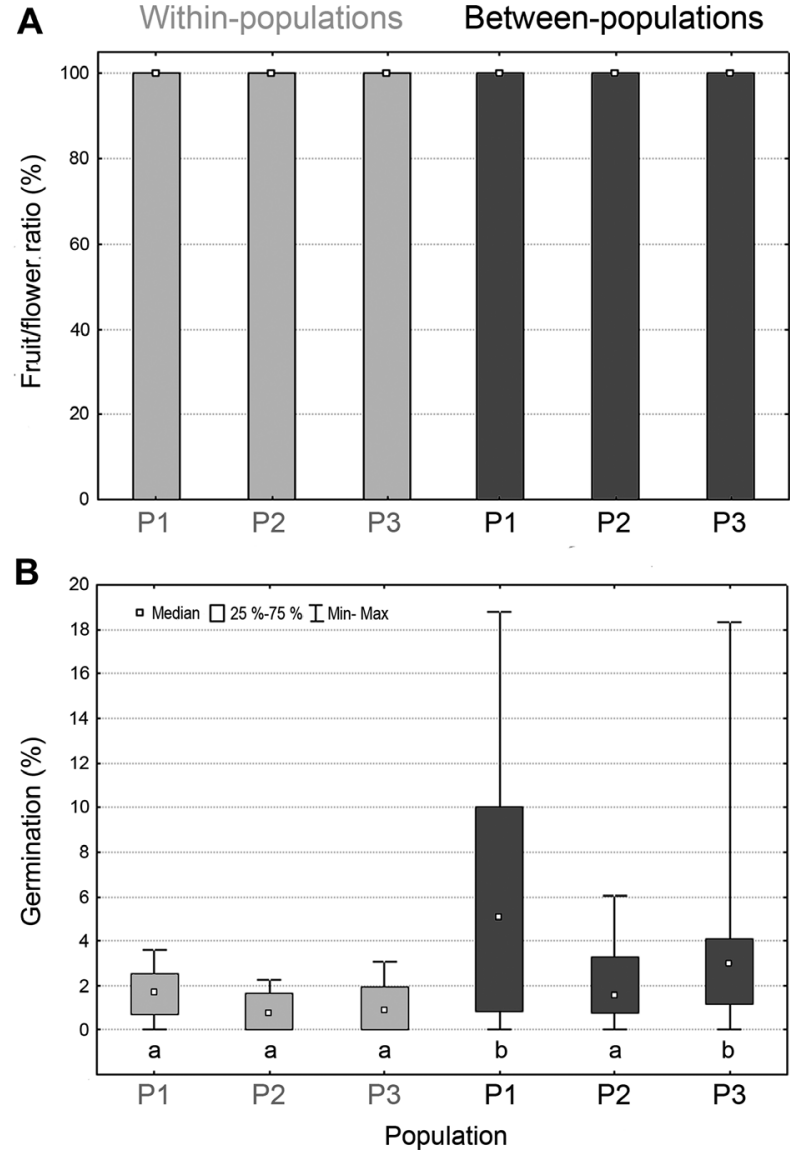

Fig. 4. Fruit/flower ratio (A) and germination percentage (B) of withinpopulation (control) and between-population (treatment) pollen transfer. Boxes with different letters are significantly different according to multiple comparison test. P4 (large population) was pollen donor for P2 and P3. P2 (small population) was the pollen donor for P1.

the reference populations, and also in the out-crossing experiment. Although species germination percentage can vary according to the site or the breeding process (e.g. Del Vecchio et al. 2012, 2018; Caruso et al. 2015), the drastic increase in both fruiting rate and germination capacity of H. adriaticum after hand-pollination suggests that pollination limitation may be a widespread phenomenon among small and isolated populations of this orchid. As a consequence of the abandonment of traditional management practices (e.g. mowing, haymaking and pasture), dry grasslands in the study area have undergone a significant decrease in surface area. Nowadays, they survive as small to medium-sized patches $(0.2-2.0 \mathrm{ha})$, surrounded by woodland, areas under cultivation (particularly vineyards), villages and industrialised areas, and the majority of orchid populations are small and exhibit fragmented distributions (Slaviero et al. 2016; Fantinato et al. 2018). In small, isolated populations, genetic flow decreases, while the chances of inbreeding increase, resulting in inbreeding depression (Frankham 2015). Detrimental effects of inbreeding can be observed at different stages of the plant life history (e.g. low production of fruit and viable seed, low total seed production per fruit, high production of empty seeds per fruit), but are often most evident at the 
germination stage, resulting in a reduced germination percentage (Ferdy et al. 2001; Smithson 2006; Sletvold et al. 2012).

The germination rate of different orchid species is highly variable (Nadarajan et al. 2011; Ponert et al. 2011; Pierce et al. 2019) and contrasting results can be obtained from laboratory and field experiments (Gilián et al. 2018). However, our results are consistent with previous research showing a very low germination percentage in the laboratory for H. adriaticum $(1.3 \%$; Gilián et al. 2018). Our results are also in line with the findings of Carey \& Farrell (2002) for the congeneric species $H$. hircinum, in which a long-term experiment demonstrated a similar germination percentage in the field $(\sim 5 \%$ in the first year, even with mycorrhizal infection). Although further research should be devoted to investigating the germination percentage in the field after hand-pollination, our study demonstrated that artificial between-population pollen transfer can enhance the germination capacity of $H$. adriaticum and thus represents a useful tool for conservation of this species, contributing to mitigation of the negative effects of small population size and isolation on genetic mechanisms (Ferdy et al. 2001; Pierce et al. 2010; Sletvold et al. 2012; Hens et al. 2017).

The results were particularly encouraging for the smallest but closest populations, since the germination percentage was increased almost four-fold, with respect to the control, following artificial out-crossing. In contrast, out-crossing performed on the small population using pollen from the largest but most distant one had a lesser effect (despite a doubling of germination with respect to the control). The beneficial effect of outbreeding on fitness has already been highlighted, with results being consistent across taxa (invertebrates, vertebrates and plants) and benefits increasing in stressful conditions (Frankham 2015). Case studies from natural populations have shown that gene flow from other populations reversed the detrimental effects of inbreeding over the short term (Arrenda et al. 2004) by increasing both fitness and population size.

Several parameters have been suggested as good predictors of plant performance for the transfer of genetic material between different populations: similarity of habitats (Bischoff et al. 2006) or overall ecological similarity of the two sites (Smith et al. 2009), geographic distance between the donor and the recipient population (e.g. Joshi et al. 2001; Becker et al. 2008) or climate difference between the donor and the recipient site (Weisshuhn et al. 2012). However, there is still substantial debate and recently Caruso et al. (2015) and Bucharova et al. (2017) found that although both geographic and climate distances were correlated with species fitness traits, there was no general pattern supporting the hypothesis that climate or geographic distance would be better predictors of plant performance than habitat similarity.

In our study we tested the effects of cross-pollination between populations growing under the same ecological condition (e.g. temperature, water availability, soil and habitat type), but differing in the geographic distance between donor and recipient population. Although it is difficult to make general predictions from small numbers of extremely rare species, our results are in agreement with the hypothesis that the distance between donor and recipient population may be a key factor in the success of artificial pollen transfer. Although contrasting results have been found (Baskin \& Baskin 2015), our results also agree with the existence of an optimal out-crossing distance for $H$. adriaticum, at which the positive and negative effects of outbreeding are balanced. The optimal distance varies according to the species, but when the individuals are too close (separated by only a few metres), the likelihood of inbreeding is very high, while crossing between very widely spaced individuals or populations increases the probability of outbreeding depression; consequently, the optimal outbreeding rate is obtained at an intermediate distance (Paschke et al. 2002; Billingham et al. 2007).

In our work, the closest populations (where the highest success of outbreeding was observed) were also the least functionally isolated, being separated by $0.5 \mathrm{~km}$ of an agricultural matrix. As has previously been demonstrated for other species, the success of outbreeding can be a function of the extent of isolation, having positive effects in less isolated and genetically similar populations (Hufford \& Mazer 2003; Raabová et al. 2007; Weisshuhn et al. 2012; Yardeni et al. 2016). In plants, gene flow occurs via migration of vegetative propagules, seeds or pollen and often depends on the foraging distances of pollinators. The most frequent pollinators of $H$. adriaticum are beetles and solitary bees (Fantinato et al. 2017), which do not travel long distances, but this orchid can also be occasionally visited by other pollinators, such as Apis mellifera, which can cover longer distances of approximately $1 \mathrm{~km}$ (Beekman \& Ratnieks 2000; Fantinato et al. 2017). We can thus assume that partial gene flow can occur between these two populations and this supports the hypothesis of higher outbreeding success in relatively similar populations.

Although our experiment did not cover the full spectrum of cross-pollination possibilities, our study has important implications in the context of restoration ecology, in particular for the choice of the most suitable areas to be selected as sources of pollen to reinforce endangered populations in restoration plans. Specifically, our results suggest that pollen for cross-pollination projects should come from the closest populations, with vicinity used as a proxy for ecological similarity.

The restoration of plant communities is often realized through the introduction of seedlings obtained from non-local populations, with the risk of introducing inappropriate alleles into locally adapted populations (Broadhurst et al. 2008; Hölzel et al. 2012). Therefore, we underline the importance of empirical studies to investigate the possible role of outbreeding in reducing this risk. Such studies would provide a practical instrument for the conservation of endangered species.

\section{REFERENCES}

Aguirre A., Dirzo R. (2008) Effects of fragmentation on pollinator abundance and fruit set of an abundant understory palm in a Mexican tropical forest. Biological Conservation, 141, 375-384.

Angeloni F., Ouborg N.J., Leimu R. (2011) Meta-analysis on the association of population size and life history with inbreeding depression in plants. Biological Conservation, 144, 35-43.

Arrenda J., Walker C.W., Sundqvist A.K., Hellborg L., Vilà C. (2004) Genetic evaluation of an otter translocation program. Conservation Genetics, 5, 79-88.

Baskin C.C., Baskin J.M. (2014) Seeds: ecology, biogeography, and evolution of dormancy and germination, 2nd edn. Academic Press, San Diego, CA, USA.
Baskin J.M., Baskin C.C. (2015) Inbreeding depression and the cost of inbreeding on seed germination. Seed Science Research, 25, 355-385.

Becker U., Dostal P., Jorritsma-Wienk L.D., Matthies D. (2008) The spatial scale of adaptive population differentiation in a widespread, well-dispersed plant species. Oikos, 117, 18651873 . 
Beekman M., Ratnieks F.L.W. (2000) Long-range foraging by the honey-bee, Apis mellifera L. Functional Ecology, 14, 490-496.

Billingham M.R., Simoes T., Reusch T.B.H., Serrao E.A. (2007) Genetic sub-structure and intermediate optimal outcrossing distance in the marine angiosperm Zostera marina. Marine Biology, 152, 793-801.

Biró É., Bódis J., Nagy T., Tökölyi J., Molnár V.A. (2015) Honeybee (Apis mellifera) mediated increased reproductive success of a rare deceptive orchid. Applied Ecology and Environmental Research, 13, 181-192.

Bischoff A., Crémieux L., Smilauerova M., Lawson C.S., Mortimer S.R., Dolezal J., Lanta V., Edwards A.R., Brook A.J., Macel M., Leps J., Steinger T., Müller-Schärer H. (2006) Detecting local adaptation in widespread grassland species - The importance of scale and local plant community. Journal of Ecology, 94, 1130-1142.

Broadhurst L.M., Lowe A., Coates D.J., Cunningham S.A., McDonald M., Vesk P.A., Yates C. (2008) Seed supply for broadscale restoration: maximizing evolutionary potential. Evolutionary Applications, 1, 587597.

Bucharova A., Michalski S., Hermann J.M., Heveling K., Durka W., Hölzel N., Kollmann J., Bossdorf O. (2017) Genetic differentiation and regional adaptation among seed origins used for grassland restoration: lessons from a multispecies transplant experiment. Journal of Applied Ecology, 54, 127-136.

Buffa G., Carpanè B., Casarotto N., Da Pozzo M., Filesi L., Lasen C., Marcucci R., Masin R., Prosser F., Tasinazzo S., Villani M., Zanatta K. (2016) Lista rossa regionale delle piante vascolari. Regione Veneto, Venezia, Italy.

Buffa G., Del Vecchio S., Fantinato E., Milano V. (2018) Local versus landscape-scale effects of anthropogenic land-use on forest species richness. Acta Oecologica, 86, 49-56.

Butcher D., Marlow S.A. (1989) Asymbiotic germination of epiphytic and terrestrial orchids. In: Pritchard H.W. (Ed.), Modern methods of orchid conservation. The role of physiology, ecology and management. Cambridge University Press, New York, USA, pp 31-38.

Carey P.D., Farrell L. (2002) Himantoglossum hircinum (L.) Sprengel. Journal of Ecology, 90, 206-218.

Caruso C.M., Benscoter A.M., Gale N.V., Seifert E.K., Mills E.R., Case A.L. (2015) Effects of crossing distance on performance of the native wildflower Lobelia siphilitica: implications for ecological restoration. Journal of the Torrey Botanical Society, 142, 140-151.

Charlesworth D., Charlesworth B. (1987) Inbreeding depression and its evolutionary consequences. Annual Review of Ecology and Systematics, 18, 237-268.

Del Vecchio S., Mattana E., Acosta A.T.R., Bacchetta G. (2012) Seed germination responses to varying environmental conditions and provenances in $\mathrm{Cru}$ cianella maritima L., a threatened coastal species. Comptes Rendus Biologies, 335, 26-31.

Del Vecchio S., Porceddu M., Fantinato E., Acosta A.T.R., Buffa G., Bacchetta G. (2018) Germination responses of Mediterranean populations of Cakile maritima to light, salinity and temperature. Folia Geobotanica, 53, 417-428.

Dostalova A., Montagnani C., Hodálová I., Jogan N., Király G., Ferakova V., Bernhardt K.G. (2013) Himantoglossum adriaticum. In: IUCN 2013. The IUCN red list of threatened species. Version 2013.2..
Available from www.iucnredlist.org. (accessed 15 October 2018).

Fantinato E., Del Vecchio S., Slaviero A., Conti L., Acosta A.T.R., Buffa G. (2016a) Does flowering synchrony contribute to the sustainment of dry grassland biodiversity? Flora, 222, 96-103.

Fantinato E., Giovanetti M., Del Vecchio S., Buffa G. (2016b) Altitudinal patterns of floral morphologies in dry calcareous grasslands. Plant Sociology, 53, 8390.

Fantinato E., Del Vecchio S., Baltieri M., Fabris B., Buffa G. (2017) Are food-deceptive orchid species really functionally specialized for pollinators? Ecological Research, 32, 951-959.

Fantinato E., Del Vecchio S., Giovanetti M., Acosta A.T.R., Buffa G. (2018) New insights into plant coexistence in species-rich communities: the pollination interaction perspective. Journal of Vegetation Science, 29, 6-14.

Fantinato E., Del Vecchio S., Gaetan G., Buffa G. (2019) The resilience of pollination interactions: importance of temporal phases. Journal of Plant Ecology, rty005, https://doi.org/10.1093/jpe/rty005.

FAO (2014) Genebank standards for plant genetic resources for food and agriculture, Revised edn. Italy, Rome.

Fekete R., Nagy T., Bódis J., Biró É., Löki V., Süveges K., Takács A., Tökölyi J., Molnár V.A. (2017) Roadside verges as habitats for endangered lizard-orchids (Himantoglossum spp.): ecological traps or refuges? Science of the Total Environment, 607-608, 10011008.

Ferdy J.B., Loriot S., Sandmeier M., Lefranc M., Raquin C. (2001) Inbreeding depression in a rare deceptive orchid. Canadian Journal of Botany, 79, 1181-1188.

Fischer J., Lindenmayer D.B. (2007) Landscape modification and habitat fragmentation: a synthesis. Global Ecology and Biogeography, 16, 265-280.

Frankham R. (2015) Genetic rescue of small inbred populations: meta-analysis reveals large and consistent benefits of gene flow. Molecular Ecology, 24, 2610-2618.

Gilián L.D., Bódis J., Eszéki E., Illyés Z., Biró É., Nagy J.G.Y. (2018) Germination traits of Adriatic lizard orchid (Himantoglossum adriaticum) in Hungary. Applied Ecology and Environmental Research, 16, $1155-1171$.

Goldman I.L. (1998) From out of old fields comes all this new corn: an historical perspective on heterosis in plant improvement. In: Larnkey K.R., Staub J.E. (Eds), Concepts and breeding of heterosis in crop plants. Crop Sciences Society of America, Madison, WI, USA, 25, pp 1-12.

Hens H., Pakanen V.M., Jäkäläniemi A., Tuomi J., Kvist L. (2017) Low population viability in small endangered orchid populations: genetic variation, seedling recruitment and stochasticity. Biological Conservation, 210, 174-183.

Hill N.M., Myra M.T.D., Johnston M.O. (2006) Breeding system and early stage inbreeding depression in a Nova Scotian population of the global rarity, Sabatia kennedyana (Gentianaceae). Rhodora, 108, 307-328.

Hölzel N., Buisson E., Dutoit T. (2012) Species introduction - a major topic in vegetation restoration. Applied Vegetation Science, 15, 161-165.

Hufford K.M., Mazer S.J. (2003) Plant ecotypes: genetic differentiation in the age of ecological restoration. Trends in Ecology \& Evolution, 18, 147155.
Jacquemyn H., Brys R. (2015) Pollen limitation and the contribution of autonomous selfing to fruit and seed set in a rewarding orchid. American Journal of Botany, 102, 67-72.

Janišová M., Bartha S., Kiehl K., Dengler J. (2011) Advances in the conservation of dry grasslands: introduction to contributions from the seventh European Dry Grassland Meeting. Plant Biosystems, 145, 507-513.

Jersáková J., Malinová T. (2007) Spatial aspects of seed dispersal and seedling recruitment in orchids. New Phytologist, 176, 237-241.

Joshi J., Schmid B., Caldeira M.C., Dimitrakopoulos P.G., Good J., Harris R., Hector A., Huss-Danell H., Jumpponen A., Minns A., Mulder C.P.H., Pereira J.S., Prinz A., Scherer-Lorenzen M., Siamantziouras A.-S.D., Terry A.C., Troumbis A.Y., Lawton J.H. (2001) Local adaptation enhances performance of common plant species. Ecology Letters, 4, 536-544.

Keller L.F., Waller D.M. (2002) Inbreeding effects in wild populations. Trends in Ecology \& Evolution, 17, 230-241.

Lienert J. (2004) Habitat fragmentation effects on fitness of plant populations - a review. Journal for Nature Conservation, 12, 53-72.

Magrini S., De Vitis M. (2017) In vitro reproduction of three Limodorum species (Orchidaceae): impacts of scarification methods and nitrogen sources on mature seed germination and seedling development. Plant Biosystems, 151, 419-428.

Malmgren S. (1996) Orchid propagation. Theory and practice. In: Allen C. (Ed.), North American native terrestrial orchids. Propagation and production. North American Native Terrestrial Orchid Conference Proceedings, Germantown, MD, USA, pp 63-71.

Nadarajan J., Wood S., Marks T.R., Seaton P.T., Pritchard H.W. (2011) Nutritional requirements for in vitro seed germination of 12 terrestrial, lithophytic and epiphytic orchids. Journal of Tropical Forest Science, 23, 204-212.

Oostermeijer J.G.B. (2003) Threats to rare plant persistence. In: Brigham C. A., Schwartz M. W. (Eds), Population viability in plants. Springer, Berlin, Germany, pp 17-43.

Paschke M., Abs C., Schmid B. (2002) Effects of population size and pollen diversity on reproductive success and offspring size in the narrow endemic Cochlearia bavarica. American Journal of Botany, 89, 1250-1259.

Pecoraro L., Girlanda M., Kull T., Perini C., Perotto S. (2013) Fungi from the roots of the terrestrial photosynthetic orchid Himantoglossum adriaticum. Plant Ecology and Evolution, 146, 145-152.

Pellissier L., Vittoz P., Internicola A.I., Gigord L.D.B. (2010) Generalized food-deceptive orchid species flower earlier and occur at lower altitudes than rewarding ones. Journal of Plant Ecology, 3, 243-250.

Pierce S., Cerabolini B.E.L. (2011) Asymbiotic germination of the White Mountain Orchid (Pseudorchis albida) from immature seed on media enriched with complex organics or phytohormones. Seed Science and Technology, 39, 199-203.

Pierce S., Ferrario A., Cerabolini B. (2010) Outbreeding and asymbiotic germination in the conservation of the endangered Italian endemic orchid Ophrys benacensis. Plant Biosystems, 144, 121-127.

Pierce S., Guidi V., Ferrario A., Ceriani R.M., Labra M., Vagge I., Cerabolini B.E.L. (2015) Pea seed extracts stimulate germination of the terrestrial 
orchid Ophrys apifera Huds. during a habitat restoration project. Plant Biosystems, 149, 54-60.

Pierce S., Spada A., Caporali E., Ceriani R.M., Buffa G. (2019) Enzymatic scarification of Anacamptis morio (Orchidaceae) seed facilitates lignin degradation, water uptake and germination. Plant Biology. https://doi.org/10.1111/plb.12694.

Ponert J., Vosolsobě S., Kmecová K., Lipavská H. (2011) European orchid cultivation - from seed to mature plant. European Journal of Environmental Science, 1, 95-107.

Raabová J., Müenzbergová Z., Fischer M. (2007) Ecological rather than geographic or genetic distance affects local adaptation of the rare perennial herb, Aster amellus. Biological Conservation, 139, 348-357.

Rasmussen H. (1995) Terrestrial orchids. From seeds to mycotrophic plant. Cambridge University Press, New York, USA.

Rasmussen H.N. (2002) Recent developments in the study of orchid mycorrhiza. Plant and Soil, 244, 149-163.
Rizzieri Masin R., Tietto C. (2006) Flora vascolare della Provincia di Padova. Natura vicentina, Vicenza, Italy, pp 7-103.

Slaviero A., Del Vecchio S., Pierce S., Fantinato E. Buffa G. (2016) Plant community attributes affect dry grassland orchid establishment. Plant Ecology, 217, 1533-1543.

Sletvold N., Grindeland J.M., Zu P.J., Ågren J. (2012) Strong inbreeding depression and local outbreeding depression in the rewarding orchid Gymnadenia conopsea. Conservation Genetics, 13 1305-1315.

Smith B.M., Diaz A., Daniels R., Winder L., Holland J.M. (2009) Regional and ecotype traits in Lotus corniculatus L., with reference to restoration ecology. Restoration Ecology, 17, 12-23.

Smithson A. (2006) Pollinator limitation and inbreeding depression in orchid species with and without nectar rewards. New Phytologist, 169, 419-430.
Spinardi A., Bassi D. (2012) Olive fertility as affected by cross-pollination and boron. Scientific World Journal, 2012, 375631, 8 pp.

Tremblay R.L., Ackerman J.D., Zimmerman J.K., Calvo R.N. (2005) Variation in sexual reproduction in orchids and its evolutionary consequences: a spasmodic journey to diversification. Biological Journal of the Linnean Society, 84, 154.

Weisshuhn K., Prati D., Fischer M., Auge H. (2012) Regional adaptation improves the performance of grassland plant communities. Basic and Applied Ecology, 13, 551-559.

Wilson J.K. (1915) Calcium hypochlorite as a seed sterilizer. American Journal of Botany, 2, 420-424.

Yardeni G., Tessler N., Imbert E., Sapir Y. (2016) Reproductive isolation between populations of Iris atropurpurea is associated with ecological differentiation. Annals of Botany, 118, 971-982. 